\title{
High-level inhibition of mitochondrial complexes III and IV is required to increase glutamate release from the nerve terminal
}

\author{
Seán M Kilbride, Sonia A Gluchowska, Jayne E Telford, Catherine O'Sullivan and Gavin P Davey*
}

\begin{abstract}
Background: The activities of mitochondrial complex III (ubiquinol-cytochrome $c$ reductase, EC 1.10.2.2) and complex IV (cytochrome c oxidase EC 1.9.3.1) are reduced by 30-70\% in Huntington's disease and Alzheimer's disease, respectively, and are associated with excitotoxic cell death in these disorders. In this study, we investigated the control that complexes III and complex IV exert on glutamate release from the isolated nerve terminal.

Results: Inhibition of complex III activity by $60-90 \%$ was necessary for a major increase in the rate of $\mathrm{Ca}^{2}$ ${ }^{+}$-independent glutamate release to occur from isolated nerve terminals (synaptosomes) depolarized with 4aminopyridine or $\mathrm{KCl}$. Similarly, an $85-90 \%$ inhibition of complex IV activity was required before a major increase in the rate of $\mathrm{Ca}^{2+}$-independent glutamate release from depolarized synaptosomes was observed. Inhibition of complex III and IV activities by 60\% and above was required before rates of glutamate efflux from polarized synaptosomes were increased.

Conclusions: These results suggest that nerve terminal mitochondria possess high reserves of complex III and IV activity and that high inhibition thresholds must be reached before excess glutamate is released from the nerve terminal. The implications of the results in the context of the relationship between electron transport chain enzyme deficiencies and excitotoxicity in neurodegenerative disorders are discussed.
\end{abstract}

\section{Background}

Glutamate excitotoxicity is thought to occur in chronic neurodegenerative disorders such as Alzheimer's disease, Parkinson's disease, Huntington's disease and amyotrophic lateral sclerosis [1,2], and dysfunction of mitochondrial electrion transport chain complexes have been implicated in the pathogenesis of these diseases [3-5]. Reductions in complex II/III activity are specific to the brain areas affected by the pathogenesis of Huntington's disease [6-8]; decreased complex II/III activity in the caudate (by 29\%) and putamen (by 67\%) was found in post-mortem brain tissue, and complex IV activity was reduced in both regions by $30 \%$ and $62 \%$ respectively $[6,9]$. Complex III deficiencies which occur as a result of rare mutations can result in the pathogenesis of encaphalpathic syndromes of various severity $[10,11]$.

\footnotetext{
* Correspondence: gdavey@tcd.ie

School of Biochemistry and Immunology \& Trinity College Institute of Neuroscience, Trinity College Dublin, Dublin 2, Ireland
}

Widespread neurodegeneration throughout the brain has been shown to occur in Alzheimer's disease, and postmortem studies on the Alzheimer brain found that complex IV activity was reduced by $27 \%$ in the cerebral cortex, by $37 \%$ in the temporal cortex, and by $52 \%$ in the hippocampus $[12,13]$. Reductions in the activities of other mitochondrial enzymes, including complex III, have also been found $[14,15]$. A decrease in complex IV activity in the brain associated with aging is also thought to occur [16-18] and insufficient control over glutamate release due to mitochondrial complex III and IV deficiency are thought to contribute to neuronal cell death $[8,19]$. During conditions of severe energy stress, release of glutamate occurs primarily via reversal of plasma membrane glutamate transporters [20]. The depletion of intracellular ATP results in plama membrane depolarization and $\mathrm{Ca}^{2+}$-independent release of glutamate from the cytoplasmic pool. The resulting increase in extracellular glutamate concentration causes post-synaptic glutamate receptor overactivation, resulting in $\mathrm{Ca}^{2+}$ 
overload and 'excitotoxic' cell death, Although most commonly associated with the pathogenesis of acute neurodegenerative disorders such as stroke and brain trauma, there is evidence suggesting that a similar 'slower' form of excitotoxicity contributes to chronic neurodegeneration [21].

Previous studies have examined the effects of total inhibition of complex IV activity using $\mathrm{NaCN}$ on glutamate release [22-25], which indicated that an increase in $\mathrm{Ca}^{2+}$-independent glutamate efflux from polarized synaptosomes occurs due to severe depletion of nerve terminal ATP content [24]. Under these conditions, insufficient ATP supply to the plasma membrane $\mathrm{Na}^{+} / \mathrm{K}$ ${ }^{+}$ATPase results in depolarization, and $\mathrm{Ca}^{2+}$-independent release of glutamate via reversal of glutamate transporters [26]. Complex I exerts a high level of flux control over oxidative phosphorylation in in situ synaptosomal mitochondria [27] and a 40\% inhibition of complex I activity results in an increase in $\mathrm{Ca}^{2+}$-independent glutamate release from depolarized synaptosomes [28]. However, the effects of partial inhibition of complexes III and IV on glutamate release from nerve terminal preparations remain unknown.

Complexes III and IV have been shown to have high thresholds of inhibition of activity before major changes in oxygen consumption and ATP production occur in isolated brain mitochondria $[29,30]$. Comparison of such data obtained from experiments carried out on isolated nerve terminal mitochondria [31] with nonsynaptic mitochondria [32,33] indicate the threshold levels are higher in synaptosomal mitochondria for both complex III and complex IV respectively. This suggests that complexes III and IV have relatively low levels of control over oxidative phosphorylation in isolated synaptosomal mitochondria. Recently we demonstrated that both complex III and complex IV have lower control over oxygen consumption in in situ synaptosomal mitochondria than complex I [27]. To examine the control of complexes III and IV over glutamate release from nerve terminals, experiments using ranges of concentrations of the complex III inhibitors myxothiazol and antimycin A, which inhibit complex III activity upstream and downstream of the Q-cycle respectively [34], and a range of concentrations of the complex IV inhibitor KCN on glutamate release rates were carried out. Such data may be relevent to elucidating the role of excitotoxicity in the pathogenesis of neurodegenerative disorders.

\section{Results}

\section{Complex III-related loss of nerve terminal control over glutamate release}

We have previously demonstrated that inhibition of complex III activity in synaptic mitochondria by up to $80 \%$ does not result in any major reductions in oxidative phosphorylation [33]. This suggests that a high threshold of inhibition of complex III activity must be exceeded before effects on mitochondrial oxygen consumption and ATP production occur. However, this threshold was found to be lower in in situ synaptosomal mitochondria [27]. A low threshold of inhibition was consistantly shown to exist for complex I $[27,35]$, which correlated to a loss of synaptosomal control over $\mathrm{Ca}^{2+}$-independent glutamate release at low level inhibition of complex I activity $[28,36]$. In the present study, we examined the downstream effects of inhibition of complex III activity on synaptosomal control over $\mathrm{Ca}^{2+}$-independent glutamate release. We found that inhibition of complex III activity by $>60 \%$ increased glutamate release to almost $250 \mathrm{pmol} / \mathrm{min} / \mathrm{mg}$ protein from synaptosomes depolarized with 4-aminopyridine (Figure 1A). However, low-level inhibition did not effect glutamate release, evidence that a complex III inhibition threshold must be exceeded before synaptosomal control over cytoplasmic glutamate retention is lost. Furthermore, inhibition by up to $80 \%$ did not affect $\mathrm{KCl}$-induced $\mathrm{Ca}^{2}$ ${ }^{+}$-independent glutamate release (Figure 1B), suggesting the occurrence of a similar threshold of inhibition to that found in isolated synaptic mitochondria. Inhibition of complex III activity by $>60 \%$ also increased glutamate efflux from synaptosomes in the absence of either depolarizing agent, although the peak rate of release was slower ( $\sim 100 \mathrm{pmol} / \mathrm{min} / \mathrm{mg}$ protein, Figure 2$)$.

Inhibition of complex III activity at the Qi site with antimycin A also increased glutamate release in depolarized synaptosomes (Figures 3A \&3B). However, inhibition by $>90 \%$ was required to elicit the increase, and a similar level of inhibition was required to increase glutamate efflux from polarized synaptosomes (Figure 4). This suggests that the inhibition thresholds that are required to be exceeded before glutamate release is effected may be heterogeneous within a single respiratory complex, depending on the site of inhibition.

\section{Complex IV-related loss of nerve terminal control over glutamate release}

It has been established that high thresholds of inhibition of complex IV activity must to be exceeded before oxygen consumption is effected in nerve terminal mitochondria, evidenced in both isolated [31,33] and in situ [27] models. Total inhibition of complex IV activity using $\mathrm{NaCN}$ has been used as a model of anoxia, and has been shown to increase glutamate efflux from resting synaptosomes $[22,23]$. Here, we used a range of concentrations of $\mathrm{KCN}$ to establish the extent that complex IV activity controls glutamate release from depolarized and polarized synaptosomes. We found that $90 \%$ inhibition of complex IV activity was required to increase the rate of $\mathrm{Ca}^{2+}$-independent glutamate release from synaptosomes depolarized with 4-aminopyridine (Figure 5A). 

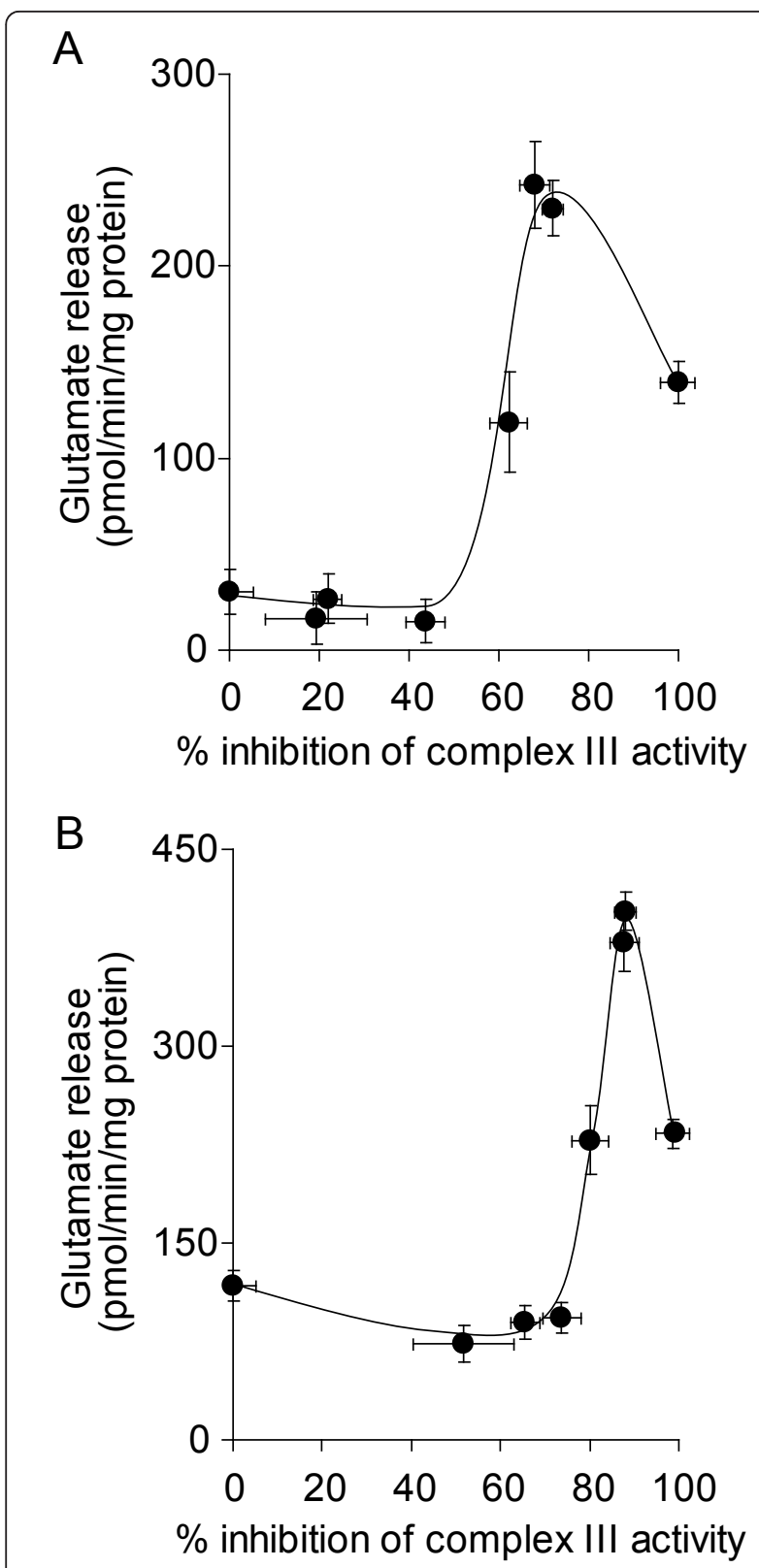

Figure 1 High-level inhibition of complex III activity with myxothiazol is required to increase the rate of glutamate release from depolarized synaptosomes. Synaptosomes $(0.5 \mathrm{mg} /$ $\mathrm{ml}$ ) were preincubated at $37^{\circ} \mathrm{C}$ for $5 \mathrm{~min}$ before being depolarized with A 1 mM 4-aminopyridine or B $40 \mathrm{mM} \mathrm{KCl}$. Rates of glutamate release at each concentration of myxothiazol were plotted against percent inhibition of complex III activity brought about by that concentration of myxothiazol. Freehand curves were drawn through the results. Points shown represent the mean \pm SEM for experiments carried out in triplicate on at least 3 separate synaptosomal preparations.

Overcoming a similarly high inhibition threshold was required to elicit an increase in glutamate release from synaptosomes depolarized with $\mathrm{KCl}$ (Figure $5 \mathrm{~B}$ ). In resting synaptosomes, in accordance with previous studies,

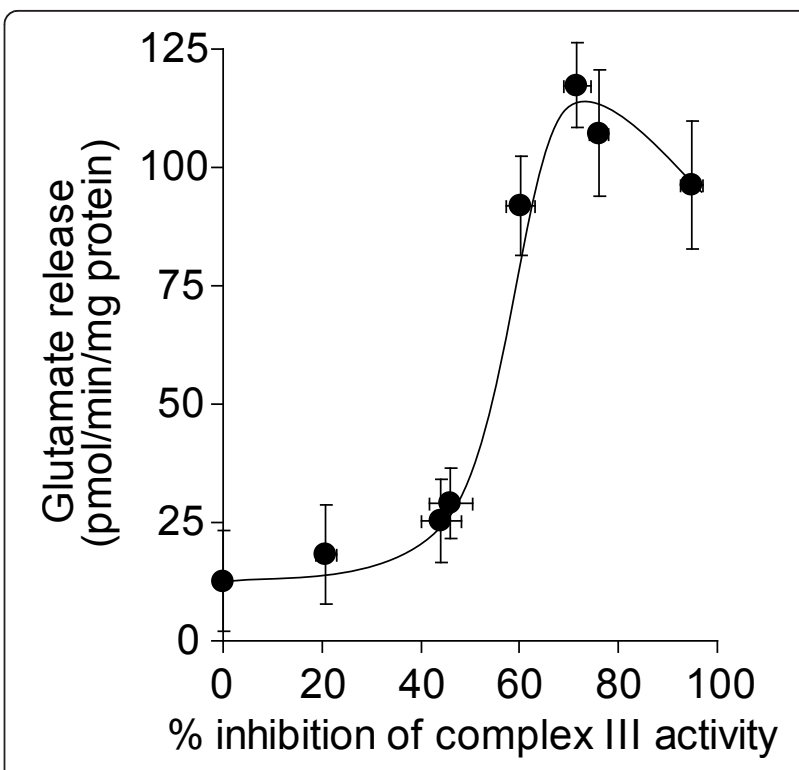

Figure 2 High-level inhibition of complex III activity with myxothiazol is required to increase the rate of glutamate efflux from polarized synaptosomes. Synaptosomes $(0.5 \mathrm{mg} / \mathrm{ml})$ were preincubated at $37^{\circ} \mathrm{C}$ for $5 \mathrm{~min}$. Rates of glutamate release at each concentration of myxothiazol were plotted against percent inhibition of complex III activity brought about by that concentration of myxothiazol. Freehand curves were drawn through the results. Points shown represent the mean \pm SEM for experiments carried out in triplicate on at least 3 separate synaptosomal preparations.

we found that $1 \mathrm{mM} \mathrm{KCN}$ increased glutamate efflux, correlating to $\sim 90 \%$ inhibition of complex IV activity (Figure 6). However, the rate was not affected by any lower concentration of $\mathrm{KCN}$.

\section{ATP depletion caused by inhibition of complex III and IV} In the absence of complex III or IV inhibitors, polarized and depolarized synaptosomes maintained their ATP levels close to control levels (Figure 7). Incubation with $50 \mathrm{nM}$ myxothiazol reduced the ATP levels to approximately $80 \%$ of the control levels in all 3 groups. Myxothiazol concentrations of 1 and $10 \mu \mathrm{M}$ lowered the ATP levels to 52 and $40 \%$ in polarized synaptosomes, respectively. However, depolarization with 4-aminopyridine potentiated the myxothiazol-induced ATP depletion to 40 and 18\% with 1 and $10 \mu \mathrm{M}$ myxothiazol, respectively. Addition of $100 \mathrm{nM}$ antimycin A reduced ATP levels to $38 \%$ in polarized synaptosomes and to $28 \%$ in depolarized synaptosomes. Inhibition of complex IV activity by 0.1 and $1 \mathrm{mM} \mathrm{KCN}$ significantly reduced ATP levels to approximately $70 \%$ and $10 \%$, respectively, in both polarized and depolarized synaptosomes.

\section{Discussion}

The results in this study indicate that high level inhibition of complex III and IV activities of in situ 


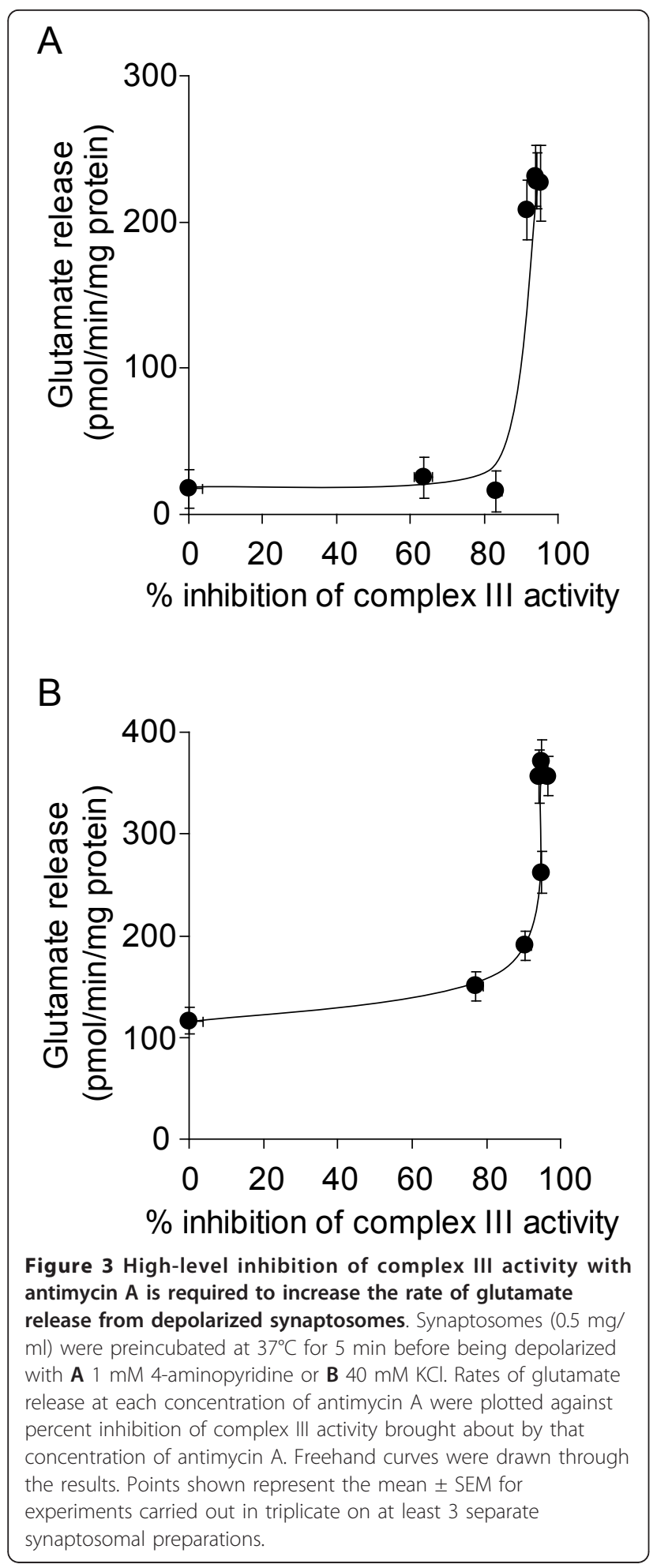

synaptosomal mitochondria are required to increase $\mathrm{Ca}^{2}$ ${ }^{+}$-independent glutamate release rates from depolarized synaptosomes, as well as the $\mathrm{Ca}^{2+}$-independent glutamate efflux rate from resting synaptsomes. Inhibition of complex III activity by more than $50 \%$ with myxothiazol

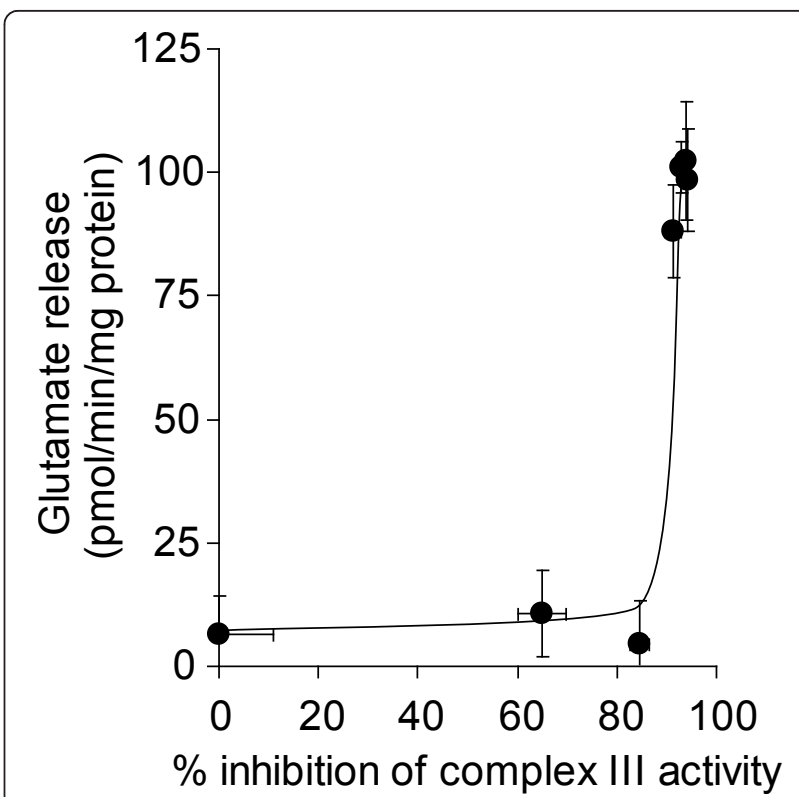

Figure 4 High level inhibition of complex III activity with antimycin $A$ is required to increase the rate of glutamate efflux from polarized synaptosomes. Synaptosomes $(0.5 \mathrm{mg} / \mathrm{ml})$ were preincubated at $37^{\circ} \mathrm{C}$ for $5 \mathrm{~min}$. Rates of glutamate release at each concentration of antimycin A were plotted against percent inhibition of complex III activity brought about by that

concentration of antimycin A. Freehand curves were drawn through the results. Points shown represent the mean \pm SEM for experiments carried out in triplicate on at least 3 separate synaptosomal preparations.

was required to increase glutamate release from depolarized and polarized synaptosomes. Complex III activity could be inhibited by up to $90 \%$ with antimycin A before $\mathrm{KCl}$ - or 4-aminopyridine-induced release or glutamate efflux was affected. A similarly high threshold of inhibition was found when complex IV was inhibited with KCN. Previously we have shown that inhibition of complex I activity by approximately $40 \%$ increases the rate of $\mathrm{Ca}^{2+}$-independent glutamate release from depolarized synaptosomes [28]. This suggests that complex I has greater control over the release cytosolic pool of glutamate in the depolarized nerve terminal model than complex III or complex IV. However, we also showed that in polarized synaptosomes, glutamate efflux was not affected by any level of inhibition of complex I activity [28], whereas in the present study it was demonstrated that inhibition of complex III or complex IV caused an increase in glutamate efflux at the highest levels of inhibition.

Using a range of myxothiazol concentrations, inhibition of complex III activity by up to $80 \%$ did not result in major changes in oxidative phosphorylation, while inhibition by $90 \%$ completely abolished the oxygen consumption and ATP production in mitochondria isolated from 

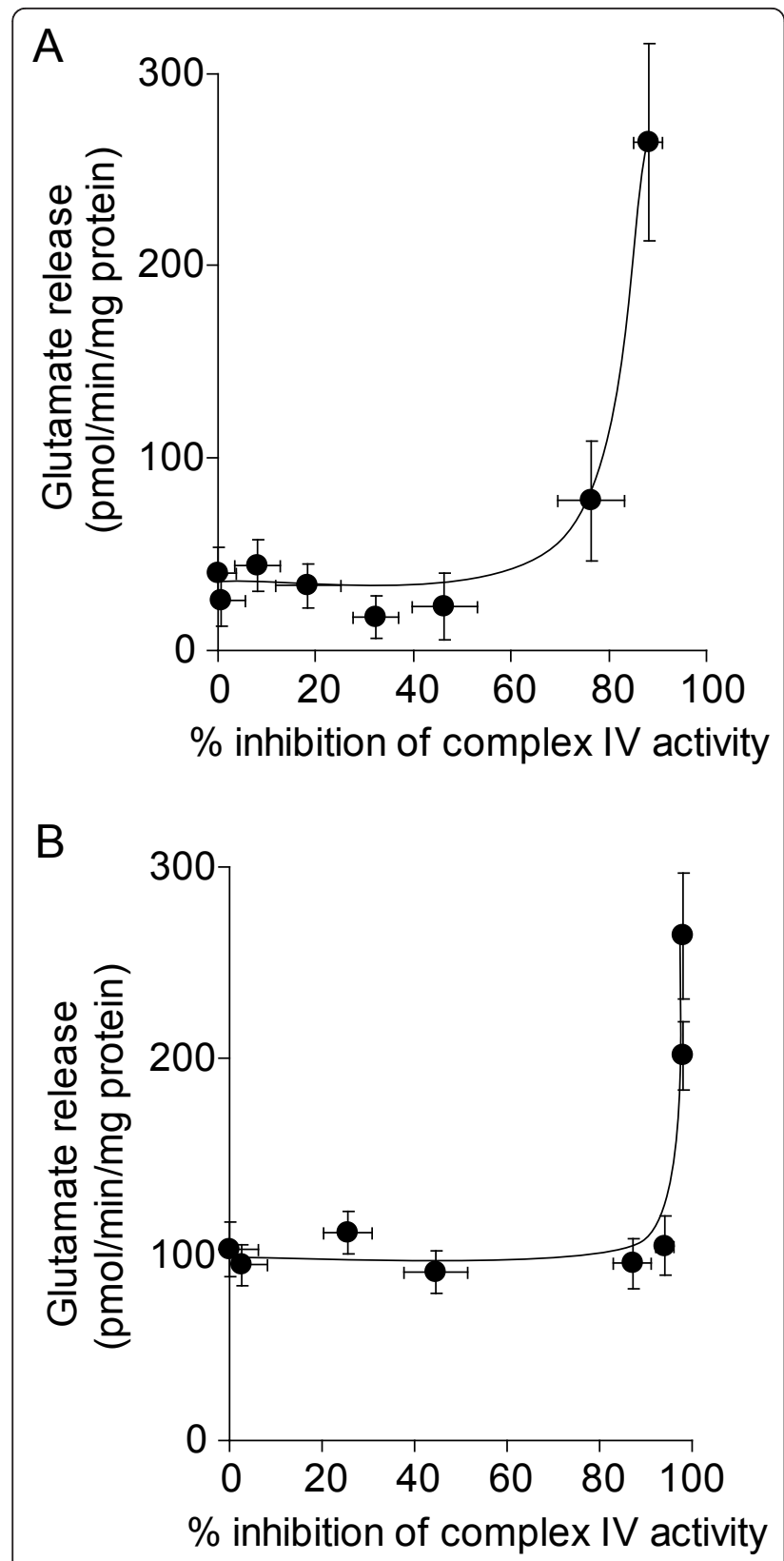

Figure 5 High-level inhibition of complex IV activity with KCN is required to increase the rate of glutamate release from depolarized synaptosomes. Synaptosomes $(0.5 \mathrm{mg} / \mathrm{ml})$ were preincubated at $37^{\circ} \mathrm{C}$ for 5 min before being depolarized with $\mathbf{A} 1$ $\mathrm{mM}$ 4-aminopyridine or $\mathbf{B} 40 \mathrm{mM} \mathrm{KCl}$. Rates of glutamate release at each concentration of $\mathrm{KCN}$ were plotted against percent inhibition of complex IV activity brought about by that concentration of KCN. Freehand curves were drawn through the results. Points shown represent the mean \pm SEM for experiments carried out in triplicate on at least 3 separate synaptosomal preparations.

synaptosomes [33]. However, the threshold level of inhibition of complex III activity on oxygen consumption in in situ synaptosomal mitochondria was found to be lower than that reported in isolated synaptic mitochondria [27].

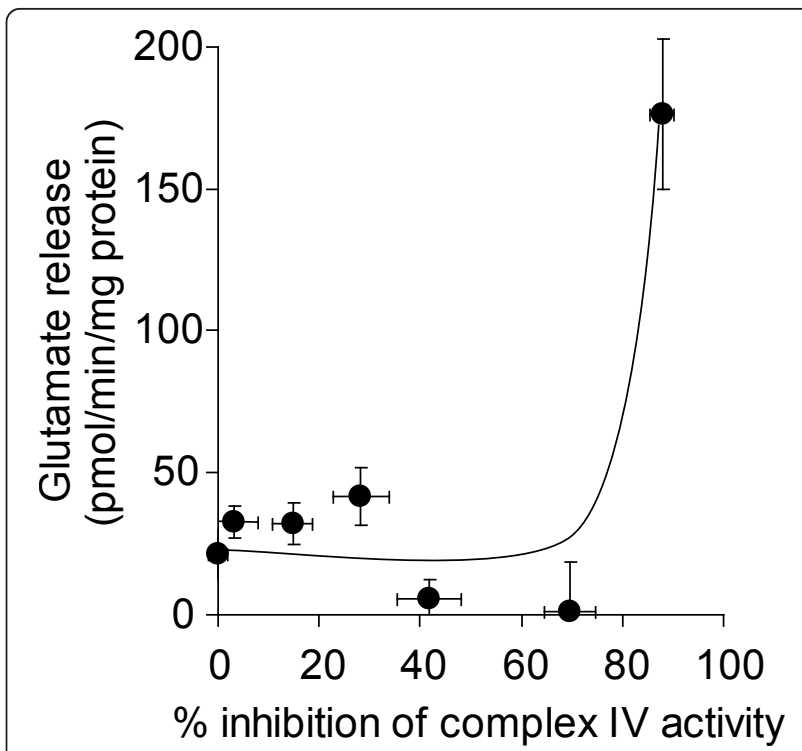

Figure 6 High-level inhibition of complex IV activity with KCN is required to increase the rate of glutamate efflux from polarized synaptosomes. Synaptosomes $(0.5 \mathrm{mg} / \mathrm{ml})$ were preincubated at $37^{\circ} \mathrm{C}$ for $5 \mathrm{~min}$ and rates of glutamate release at each concentration of KCN were plotted against percent inhibition of complex IV activity brought about by that concentration of KCN. Freehand curves were drawn through the results. Points shown represent the mean \pm SEM for experiments carried out in triplicate on at least 3 separate synaptosomal preparations.

In the in situ synaptosomal mitochondrial model, inhibition of complex III activity by $70 \%$ with myxothiazol was found to almost completely abolish the oxygen consumption rate [27]. At this level of inhibition mitochondrial ATP synthesis is also minimal (as oxygen consumption is tightly coupled to ATP synthesis in nerve terminals [37]). In the present study we found that ATP levels in polarized synaptosomes were decreased by $60 \%$ by $10 \mu \mathrm{M}$ myxothiazol. Under resting conditions glycolysis is thought to account for the remaining ATP synthesis [37]. Glutamate efflux from 'polarized' synaptosomes was found to occur at a maximum of $70 \%$ inhibition of complex III activity and $\mathrm{Ca} 2+$-independent glutamate release from synaptosomes depolarized with 4-aminopyridine over the same range of inhibition of complex III activity with myxothiazol (between $50-70 \%$ ) was 2.5-fold higher than from polarized synaptosomes. This increase in the rate of glutamate release correlated with an extra $20 \%$ reduction in ATP levels induced by 4-aminopyridine in combination with myxothiazol-related inhibition of complex III activity. This suggests that the control of complex III over oxidative phosphorylation in synaptosomes is similar to the control of complex III over glutamate release rates from synaptosomes.

Interestingly, glutamate release returned towards control levels as inhibition of complex III neared 100\%. 


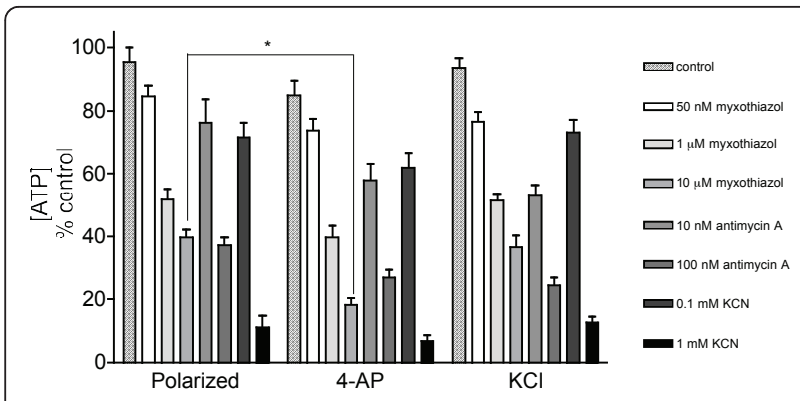

Figure 7 Partial inhibition of complexes III and IV depletes ATP levels in synaptosomes. Synaptosomes $(0.5 \mathrm{mg} / \mathrm{mL})$ were divided into groups and incubated at $37^{\circ} \mathrm{C}$ with $10 \mathrm{mM}$ glucose and inhibitors as indicated. ATP from polarized synaptosomes was PCA extracted after $15 \mathrm{~min}$ incubation. In the depolarised groups 4-AP and $\mathrm{KCl}$ were added following 5 min incubation with inhibitors. Results are expressed as a percentage of the initial [ATP] at zero time $(439.4 \pm 42.6 \mathrm{pmol} / \mathrm{mg}$ protein) and represent the mean \pm SEM for experiments carried out on three separate synaptosomal preparations. ${ }^{*} p<0.05$

This is similar to the effect observed on $\mathrm{Ca}^{2+}$-independent glutamate release from depolarized synaptosomes following inhibition of complex I activity [28]. A shortterm plasma membrane potential hyperpolarization response by neurons to extreme energy stress has been previously demonstrated [39]. This phenomenon may be related to the presence of ATP-sensitive $\mathrm{K}^{+}$channels on the plasma membrane [38], which open during periods of severe ATP depletion (correlating to an approximately $90 \%$ reduction in ATP levels in our experiments), and are thought to allow short term maintainance of the $\mathrm{K}^{+}$gradient across the plasma membrane when the $\mathrm{Na}$ ${ }^{+} / \mathrm{K}^{+}$ATPase activity is compromised [39].

The highest rates of $\mathrm{Ca}^{2+}$-independent glutamate release brought about by complex III inhibition with antimycin A were similar to those with myxothiazol. However, $80 \%$ inhibition of complex III activity with antimycin A did not increase $\mathrm{Ca}^{2+}$-independent glutamate release rates from synaptosomes depolarized with 4-aminopyridine, while maximum 4-aminopyridineinduced glutamate release rates were recorded at less than $80 \%$ inhibition of complex III activity with myxothiazol. Similarly, $80 \%$ inhibition of complex III activity with antimycin A did not increase glutamate efflux rates from 'polarized' synaptosomes while maximum glutamate efflux rates were recorded at less than $80 \%$ inhibition of complex III activity with myxothiazol. This suggests that complex III of in situ nerve terminal mitochondria may have a lower energy threshold when inhibited upstream of the Q-cycle with myxothiazol than when inhibited downstream with antimycin A, which results in increased rates of glutamate release at a lower level of inhibition.
Inhibition of complex IV activity by $>90 \%$ with $\mathrm{KCN}$ also increased $\mathrm{Ca}^{2+}$-independent glutamate release rates from synaptosomes depolarized with 4-aminopyridine or $\mathrm{KCl}$, and increased glutamate efflux from 'polarized' synaptosomes. A similar increase in glutamate efflux has previously been reported in rat brain synaptosomes when $2 \mathrm{mM} \mathrm{NaCN}$ was added, and was related to a fall in ATP/ADP ratio [24]. Inhibition of complex IV activity by up to $70 \%$ with $\mathrm{KCN}$ in isolated synaptosomal mitochondria has previously been shown to decrease ATP production by less than $10 \%$, with total inhibition of ATP production at $90 \%$ inhibition of complex IV activity [33]. The similar threshold effect found in in situ synaptosomal mitochondria [27] might explain the effects of complex IV inhibition on $\mathrm{Ca}^{2+}$-independent glutamate release from depolarized synaptosomes.

\section{Conclusions}

Reduced complex II/III activity may play a role in the excitotoxic mechanism thought to occur during the pathogenesis of Huntington's disease [6-8], and reduced complex IV activity has been consistantly observed in post mortem Alzheimer's disease brain samples [14]. Neurodegeneration has been proposed to progress from the nerve terminal to the neuronal soma in these chronic neurdegenerative disorders [40]. Indeed, ETC enzyme activities in the brain have been shown to be reduced as part of the aging process [41,42]. However, the model of the effects of reduced activities of complex III and complex IV nerve terminal glutamate release in the present study indicate that these enzymes must be inhibited by at least $50 \%$ (for complex III) or $90 \%$ (for complex IV) before major increases in glutamate release rates are observed. Such large reductions in activity are usually related to mutations in either the mitochondrial or nuclear DNA encoding components of the complexes, and usually result in severe metabolic disorders which are often fatal $[10,11]$. However, our model may support a role for excessive nerve terminal glutamate release during pathogenesis of encephalopathies caused by complex III and IV deficiencies, in which seizures are commonly reported.

A lower level of inhibition of complex I activity is required to reduce nerve terminal oxygen consumption [27] and increase $\mathrm{Ca}^{2+}$-independent glutamate release rates from depolarized nerve terminals than complex III or IV [28]. Nonetheless, inhibition of complex I activity by up to $100 \%$ did not affect glutamate efflux from resting synaptosomes [28], while inhibition of complexes III and IV increased the efflux rate, although a high level of inhibition was required. This indicates that both complex III and complex IV exert greater control over glutamate release from resting nerve terminals than complex I. However, given that the complex I threshold for $\mathrm{Ca}^{2}$ 
${ }^{+}$-independent glutamate release in depolarized synaptosomes isolated from aged rats is even lower than that from young rats [36] coupled with the findings that complex I activity is decreased in mitochondria isolated from Parkinson's disease post mortem samples [43-45], the evidence is mounting that of the ETC enzymes that are found to be reduced in the most common chronic neurodegenerative disorders, complex I is the most important.

\section{Materials and methods Materials}

Chemicals were supplied by Sigma Chemical Co., Poole, Dorset, UK or BDH, Dagenham, Essex, UK. Female Wistar rats (200-250 g) were supplied by the Bioresources Unit, Biochemistry Department, Trinity College, Dublin.

\section{Synaptosomal preparation}

Rats were killed by cervical dislocation and synaptosomes were prepared using a discontinuous ficoll gradient $(7.5 \% \mathrm{w} / \mathrm{v}$ and $10 \% \mathrm{w} / \mathrm{v})$, acording to the method of Lai and Clark [46]. Synaptosomes (1 mg) were resuspended in TES buffer (250 mM sucrose/5 mM TES, pH 7.4) and following centrifugation at $15000 \mathrm{~g}$ for $5 \mathrm{~min}$ were stored as $1 \mathrm{mg}$ pellets on ice for use within 2 hours of preparation. All experiments were carried out on at least 3 separate synaptosomal preparations to ensure reproducibility of results.

\section{Glutamate release}

Glutamate release was measured on a SpectraMAX GeminiXS (Molecular Devices, CA) well plate reader using a continuous flourimetric assay modified from that described by Nicholls et al. [47]. Synaptosomal pellets were resuspended in $1 \mathrm{ml}$ of incubation medium (3 $\mathrm{mM} \mathrm{KCl,} 140 \mathrm{mM} \mathrm{NaCl}, 25 \mathrm{mM}$ Tris- $\mathrm{HCl}, 10 \mathrm{mM}$ glucose, $\left.2 \mathrm{mM} \mathrm{MgCl}_{2}, \mathrm{pH} 7.4\right) .100 \mu \mathrm{l}$ of incubation medium containing $2 \mathrm{mM} \mathrm{NADP}{ }^{+}, 6.32 \mathrm{U}$ L-glutamic dehydrogenase, (and $1.4 \mathrm{mM} \mathrm{CaCl}_{2}$ where appropriate) was distributed into each of the 96 wells. $2 \mu$ of each respective mitochondrial electron transport chain enzyme inhibitor (final concentrations as follows: myxothiazol, $10 \mathrm{nM}-10 \mu \mathrm{M}$; antimycin A, $1 \mathrm{nM}-1 \mu \mathrm{M}$; or $\mathrm{KCN}, 1 \mu \mathrm{M}-1 \mathrm{mM}$;) was added followed by $100 \mu \mathrm{l}$ of resuspended synaptosomes (final concentration $0.5 \mathrm{mg}$ / $\mathrm{ml}$ ) and each experimental condition was carried out in triplicate on each plate. Synaptosomes were depolarized after 5 minutes and rate of increase in NADPH fluorescence at $\lambda=460 \mathrm{~nm}$ emission (340 $\mathrm{nm}$ excitation) was recorded over a 20 minute time period at a 32 second interval following depolarization. Linear rates were fitted to the traces by the SoftMax Pro program, which accompanies the instrument, and these rates were calibrated using a standard curve. Enzyme lag [47] was accounted for when converting rates to $\mathrm{nmol} / \mathrm{min} / \mathrm{mg}$ protein.

\section{Complex III activity assay}

Complex III activity was measured using a SpectraMAX 340PC well-plate spectrophotometer. The titration of complex III activity with myxothiazol (10 nM - $10 \mu \mathrm{M})$ or antimycin A (1 nM - $1 \mu \mathrm{M})$ was carried out identically to the glutamate release experiments in which synaptosomes $(0.5 \mathrm{mg} / \mathrm{ml})$ were incubated with inhibitor a final volume of $202 \mu \mathrm{l}$. Samples were frozen at $-80^{\circ} \mathrm{C}$ and subsequently underwent 3 rapid freeze-thaw cycles. Complex III activity was determined by following the reduction of cytochrome $c$ at absorbance $\lambda=550 \mathrm{~nm}$. Decylubiquinol was used as the electron donor and was prepared by reducing decylubiquinone with sodium borohydride and extraction under nitrogen in cylohexane/ diehyl ether. Wells were prepared by addition of medium containing $100 \mathrm{mM}$ potassium phosphate, $0.3 \mathrm{mM}$ potassium-EDTA, (pH 7.4), $1 \mathrm{mM} \mathrm{KCN}$ and $100 \mu \mathrm{M}$ cytochrome $c$ with a final volume of $200 \mu \mathrm{l}$. The reaction was initiated by the addition of sample $(10 \mu \mathrm{g})$ and results were expressed as a percentage of first order decay rate constants $(\mathrm{k})$.

\section{Complex IV activity assay}

Complex IV activity was measured using an Agilent ChemStation 8453 spectrophotometer. The titration of complex IV activity with KCN was also carried out identically to the glutamate release experiments, where synaptosomes $(0.5 \mathrm{mg} / \mathrm{ml})$ were incubated in a final volume of $202 \mu \mathrm{l}$ with inhibitor. After freezing at $-80^{\circ} \mathrm{C}$ and undergoing 3 rapid freeze-thaw cycles, the activity of complex IV was determined using the method of Wharton and Tzagoloff [48]: The oxidation of cytochrome $c$ at absorbance $\lambda=550 \mathrm{~nm}$ was followed. Reduced cytochrome $c$ was prepared by the addition a few crystals of ascorbic acid to oxidised cytochrome $c$ (25 $\mathrm{mg} / 2.5 \mathrm{ml}$ in $\mathrm{H}_{2} \mathrm{O}$ ). Excess ascorbic acid was removed by passing the cytochrome $c$ sample through a $\mathrm{PD}_{10}$ gel filtration column, which had been pre-rinsed

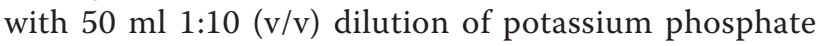
buffer $(100 \mathrm{mM}), \mathrm{pH}$ 7.0. The assay cuvettes contained $50 \mu \mathrm{M}$ reduced cytochrome $c$ and $100 \mu \mathrm{l}$ buffer with a final volume of $1 \mathrm{ml}$ made up with $\mathrm{H}_{2} \mathrm{O}$. The reaction was initiated by the addition of $50 \mu \mathrm{g}$ synaptosomal samples. The results were expressed as a percentage of first order decay rate constants $(\mathrm{k})$.

\section{ATP determinations}

ATP levels were determined using a luciferase coupled assay [28]. Synaptosomes $(1 \mathrm{mg} / \mathrm{mL})$ were pre-incubated at $37^{\circ} \mathrm{C}$ for $5 \mathrm{~min}$ in incubation medium containing 10 
$\mathrm{mM}$ glucose. After 5 min $100 \mu \mathrm{L}$ synaptosomes were added to $100 \mu \mathrm{L}$ of incubation medium with $2 \mu \mathrm{L}$ myxothiazol, antimycin or $\mathrm{KCN}$ added, where appropriate. One group was prepared for ATP determination immediately at this point, by adding $10 \mu \mathrm{L} 6.5 \mathrm{M}$ perchloric acid and, after centrifugation, neutralizing $150 \mu \mathrm{L}$ of supernatant with $375 \mu \mathrm{L} 1 \mathrm{M} \mathrm{K}_{2} \mathrm{HPO}_{4}$. Another group was depolarized after $5 \mathrm{~min}$ (with $1 \mathrm{mM} \mathrm{4-aminopyri-}$ dine). [ATP] is expressed as a percentage of the control group that contained no complex III or IV inhibitors. These groups were perchloric acid extracted in the same way 10 min after depolarization and all samples were then stored at $-80^{\circ} \mathrm{C} .10 \mu \mathrm{L}$ of extract was added to 100 $\mu \mathrm{L}$ reconstituted luciferin/luciferase ENLITEN ${ }^{\circledR}$ reagent and read immediately at $560 \mathrm{~nm}$. All samples were assayed within 1 week of preparation.

\section{Statistical analysis}

Results presented are mean \pm SEM values. Statistical analysis of the results were determined by doing a oneway ANOVA followed by a Newman-Keuls post-hoc test. Values of $\mathrm{p}<0.05$ were taken to be significant.

\section{Acknowledgements}

This work was supported by a Marie Curie Transfer of Knowledge Grant MTKD-CT-2005-030005 and by The Parkinson's Association of Ireland.

\section{Authors' contributions}

SMK, SAG, JET and COS did all experimental work. SMK wrote the manuscript. GPD conceived of the study, and participated in its design and coordination and co-wrote the manuscript. All authors read and approved the final manuscript.

\section{Competing interests}

The authors declare that they have no competing interests.

Received: 24 August 2010 Accepted: 26 July 2011

Published: 26 July 2011

\section{References}

1. Beal MF: Mechanisms of excitotoxicity in neurologic diseases. Faseb J 1992, 6:3338-3344

2. Mattson MP: Excitotoxic and excitoprotective mechanisms: abundant targets for the prevention and treatment of neurodegenerative disorders. Neuromolecular Med 2003, 3:65-94.

3. Beal MF: Mitochondria take center stage in aging and neurodegeneration. Ann Neurol 2005, 58:495-505.

4. Lin MT, Beal MF: Mitochondrial dysfunction and oxidative stress in neurodegenerative diseases. Nature 2006, 443:787-795.

5. Schapira AH, DiMauro S: Mitochondrial Disorders in Neurology 2 Boston: Bufferworth Heinemann; 2002.

6. Browne SE, Bowling AC, MacGarvey U, Baik MJ, Berger SC, Muqit MM, Bird ED, Beal MF: Oxidative damage and metabolic dysfunction in Huntington's disease: selective vulnerability of the basal ganglia. Ann Neurol 1997, 41:646-653.

7. Mann VM, Cooper JM, Javoy-Agid F, Agid Y, Jenner P, Schapira AH: Mitochondrial function and parental sex effect in Huntington's disease. Lancet 1990, 336:749.

8. Tabrizi SJ, Cleeter MW, Xuereb J, Taanman JW, Cooper JM, Schapira AH: Biochemical abnormalities and excitotoxicity in Huntington's disease brain. Ann Neurol 1999, 45:25-32.

9. Brennan WA Jr, Bird ED, Aprille JR: Regional mitochondrial respiratory activity in Huntington's disease brain. J Neurochem 1985, 44:1948-1950.
10. Benit $P$, Lebon $S$, Rustin P: Respiratory-chain diseases related to complex III deficiency. Biochim Biophys Acta 2009, 1793:181-185.

11. Borisov VB: Defects in mitochondrial respiratory complexes III and IV, and human pathologies. Mol Aspects Med 2002, 23:385-412.

12. Maurer I, Zierz S, Moller HJ: A selective defect of cytochrome c oxidase is present in brain of Alzheimer disease patients. Neurobiol Aging 2000, 21:455-462.

13. Kish SJ, Bergeron C, Rajput A, Dozic S, Mastrogiacomo F, Chang $\sqcup$, Wilson JM, DiStefano LM, Nobrega JN: Brain cytochrome oxidase in Alzheimer's disease. J Neurochem 1992, 59:776-779.

14. Parker WD Jr, Parks J, Filley CM, Kleinschmidt-DeMasters BK: Electron transport chain defects in Alzheimer's disease brain. Neurology 1994, 44:1090-1096.

15. Parihar MS, Brewer GJ: Mitoenergetic failure in Alzheimer disease. Am J Physiol Cell Physiol 2007, 292:C8-23.

16. Benzi G, Pastoris O, Marzatico F, Villa RF, Dagani F, Curti D: The mitochondrial electron transfer alteration as a factor involved in the brain aging. Neurobiol Aging 1992, 13:361-368.

17. Kwong LK, Sohal RS: Age-related changes in activities of mitochondrial electron transport complexes in various tissues of the mouse. Arch Biochem Biophys 2000, 373:16-22.

18. Navarro A, Sanchez Del Pino MJ, Gomez C, Peralta JL, Boveris A: Behavioral dysfunction, brain oxidative stress, and impaired mitochondrial electron transfer in aging mice. Am J Physiol Regul Integr Comp Physiol 2002, 282: R985-992.

19. Schapira AH: Mitochondrial involvement in Parkinson's disease, Huntington's disease, hereditary spastic paraplegia and Friedreich's ataxia. Biochim Biophys Acta 1999, 1410:159-170.

20. Rossi DJ, Oshima T, Attwell D: Glutamate release in severe brain ischaemia is mainly by reversed uptake. Nature 2000, 403:316-321.

21. Beal MF: Role of excitotoxicity in human neurological disease. Curr Opin Neurobiol 1992, 2:657-662.

22. Santos MS, Moreno AJ, Carvalho AP: Relationships between ATP depletion, membrane potential, and the release of neurotransmitters in rat nerve terminals. An in vitro study under conditions that mimic anoxia, hypoglycemia, and ischemia. Stroke 1996, 27:941-950.

23. Rubio I, Torres M, Miras-Portugal MT, Sanchez-Prieto J: $\mathrm{Ca}^{2+}$-independent release of glutamate during in vitro anoxia in isolated nerve terminals. J Neurochem 1991, 57:1159-1164.

24. Sanchez-Prieto J, Gonzalez P: Occurrence of a large $\mathrm{Ca}^{2+}$-independent release of glutamate during anoxia in isolated nerve terminals (synaptosomes). J Neurochem 1988, 50:1322-1324.

25. Sanchez-Prieto J, Sihra TS, Nicholls DG: Characterization of the exocytotic release of glutamate from guinea-pig cerebral cortical synaptosomes. $J$ Neurochem 1987, 49:58-64.

26. Nicholls DG, Budd SL: Mitochondria and neuronal survival. Physiol Rev 2000, 80:315-360

27. Telford JE, Kilbride SM, Davey GP: Complex I Is Rate-limiting for Oxygen Consumption in the Nerve Terminal. J Biol Chem 2009, 284:9109-9114.

28. Kilbride SM, Telford JE, Tipton KF, Davey GP: Partial inhibition of complex I activity increases $\mathrm{Ca}^{2+}$-independent glutamate release rates from depolarized synaptosomes. J Neurochem 2008, 106:826-834.

29. Rossignol R, Malgat M, Mazat JP, Letellier T: Threshold effect and tissue specificity. Implication for mitochondrial cytopathies. J Biol Chem 1999, 274:33426-33432

30. Mazat JP, Rossignol R, Malgat M, Rocher C, Faustin B, Letellier T: What do mitochondrial diseases teach us about normal mitochondrial functions... that we already knew: threshold expression of mitochondrial defects. Biochim Biophys Acta 2001, 1504:20-30.

31. Davey GP, Canevari L, Clark JB: Threshold effects in synaptosomal and nonsynaptic mitochondria from hippocampal CA1 and paramedian neocortex brain regions. J Neurochem 1997, 69:2564-2570.

32. Davey GP, Clark JB: Threshold effects and control of oxidative phosphorylation in nonsynaptic rat brain mitochondria. J Neurochem 1996, 66:1617-1624.

33. Davey GP, Peuchen S, Clark JB: Energy thresholds in brain mitochondria. Potential involvement in neurodegeneration. J Biol Chem 1998, 273:12753-12757.

34. von Jagow G, Ljungdahl PO, Graf P, Ohnishi T, Trumpower BL: An inhibitor of mitochondrial respiration which binds to cytochrome $b$ and displaces 
quinone from the iron-sulfur protein of the cytochrome bc1 complex. $J$ Biol Chem 1984, 259:6318-6326.

35. Telford JE, Kilbride SM, Davey GP: Decylubiquinone increases mitochondrial function in synaptosomes. J Biol Chem 2010, 285:8639-8645.

36. Kilbride SM, Telford JE, Davey GP: Age-related changes in $\mathrm{H}_{2} \mathrm{O}_{2}$ production and bioenergetics in rat brain synaptosomes. Biochim Biophys Acta 2008, 1777:783-788.

37. Kauppinen RA, Nicholls DG: Synaptosomal bioenergetics. The role of glycolysis, pyruvate oxidation and responses to hypoglycaemia. Eur J Biochem 1986, 158:159-165.

38. Ashcroft SJ, Ashcroft FM: Properties and functions of ATP-sensitive Kchannels. Cell Signal 1990, 2:197-214.

39. Jiang C, Haddad GG: Modulation of K+ channels by intracellular ATP in human neocortical neurons. J Neurophysiol 1997, 77:93-102.

40. Mattson MP, Keller JN, Begley JG: Evidence for synaptic apoptosis. Exp Neurol 1998, 153:35-48

41. Jones TT, Brewer GJ: Age-related deficiencies in complex I endogenous substrate availability and reserve capacity of complex IV in cortical neuron electron transport. Biochim Biophys Acta 2010, 1797:167-176.

42. Boveris A, Navarro A: Brain mitochondrial dysfunction in aging. IUBMB Life 2008, 60:308-314.

43. Keeney PM, Xie J, Capaldi RA, Bennett JP Jr: Parkinson's disease brain mitochondrial complex I has oxidatively damaged subunits and is functionally impaired and misassembled. J Neurosci 2006, 26:5256-5264.

44. Schapira AH, Mann VM, Cooper JM, Dexter D, Daniel SE, Jenner P, Clark JB, Marsden CD: Anatomic and disease specificity of NADH CoQ1 reductase (complex I) deficiency in Parkinson's disease. J Neurochem 1990, 55:2142-2145.

45. Parker WD Jr, Parks JK, Swerdlow RH: Complex I deficiency in Parkinson's disease frontal cortex. Brain Res 2008, 1189:215-218.

46. Lai JC, Clark JB: Isocitrate dehydrogenase and malate dehydrogenase in synaptic and non-synaptic rat brain mitochondria: a comparison of their kinetic constants. Biochem Soc Trans 1978, 6:993-995.

47. Nicholls DG, Sihra TS, Sanchez-Prieto J: Calcium-dependent and -independent release of glutamate from synaptosomes monitored by continuous fluorometry. J Neurochem 1987, 49:50-57.

48. Wharton DC, Tzagoloff A: Cytochrome Oxidase from beef heart mitochondria. Methods Enzymol 1967, 10:245-250.

doi:10.1186/1750-1326-6-53

Cite this article as: Kilbride et al: High-level inhibition of mitochondrial complexes III and IV is required to increase glutamate release from the nerve terminal. Molecular Neurodegeneration 2011 6:53.

\section{Submit your next manuscript to BioMed Central and take full advantage of:}

- Convenient online submission

- Thorough peer review

- No space constraints or color figure charges

- Immediate publication on acceptance

- Inclusion in PubMed, CAS, Scopus and Google Scholar

- Research which is freely available for redistribution

Submit your manuscript at www.biomedcentral.com/submit
Biomed Central 